\title{
WHICH REALITY DO WE MEASURE?
}

\author{
P. WEINGART, R. SEHRINGER, M. WINTERHAGER \\ Universität Bielefeld, Universitätsschwerpunkt Wissenschaftsforschung, \\ Postfach 8640, D-4800 Bielefeld (FRG)
}

\begin{abstract}
Scientific reality is a multi-sided phenomenon which cannot be described in a single and authoritative way. The descriptions of scientific research areas differ if one compares the definitions of science policy programmes with expert judgments in the peer-review process. Bibliometric measurements function as an intermediate representation of science. To make them useful and compatible with other representations they have to be translated. The difficulties of mutual translation of these different delineations of scientific research areas are demonstrated in two case studies (marine sciences and multiple sclerosis research) where each of these three different representations of science is supported by empirical results.
\end{abstract}

\section{Representations of science}

Everyone using bibliometric analyses for the evaluation of science has encountered the situation that someone in the crowd of sceptical onlookers, most often a natural scientist well experienced in making bold reductions, using mathematical models and ridiculing humanists for their fear of numbers, will stand up and raise the issue that the citation count, the co-citation analysis or some other exercise "does not capture the essence" of the particular research in question. While it is perhaps surprising to hear someone like that ask for the "essence" of science and, thus, relatively easy to reveal the self-interested rationalizing nature of this argument, one problem behind it is real. The question is, indeed, what aspect of science is being represented by the bibliometric data? In particular, when looking at the output of cocitation analysis the problem occurs that the 'research fronts' and cluster cores bear titles which, being given by experts to capture the contents of the documents contained in them, have very little or, even worse, virtually no resemblance to codifications that occur anywhere else. Our critical scientist may then come back alleging that, essence or not, at least we do not know what we are measuring. The problem of the method is to translate the data output back into the terms of "the real world".

For both theoretical and practical reasons the first question should be dealt with in an elementary way. Examples from a research project ${ }^{1}$ will serve as illustrations for the solution of the second problem. 
In the practical operation of providing bibliometric data for the evaluation of research the question of the "essential" representation of a particular segment of science is dissolved by default. Obviously, there are codifications of research fields and specialities in the science policy arena which serve to channel funds and to account for available resources and money spent, i.e. to guide decisions and serve as legitimation. These labels probably represent the negotiations between scientists, science administrators and policy makers for their particular purposes (cf. Fig. 1). They are the representation of science on a macro-structural level (level 1).

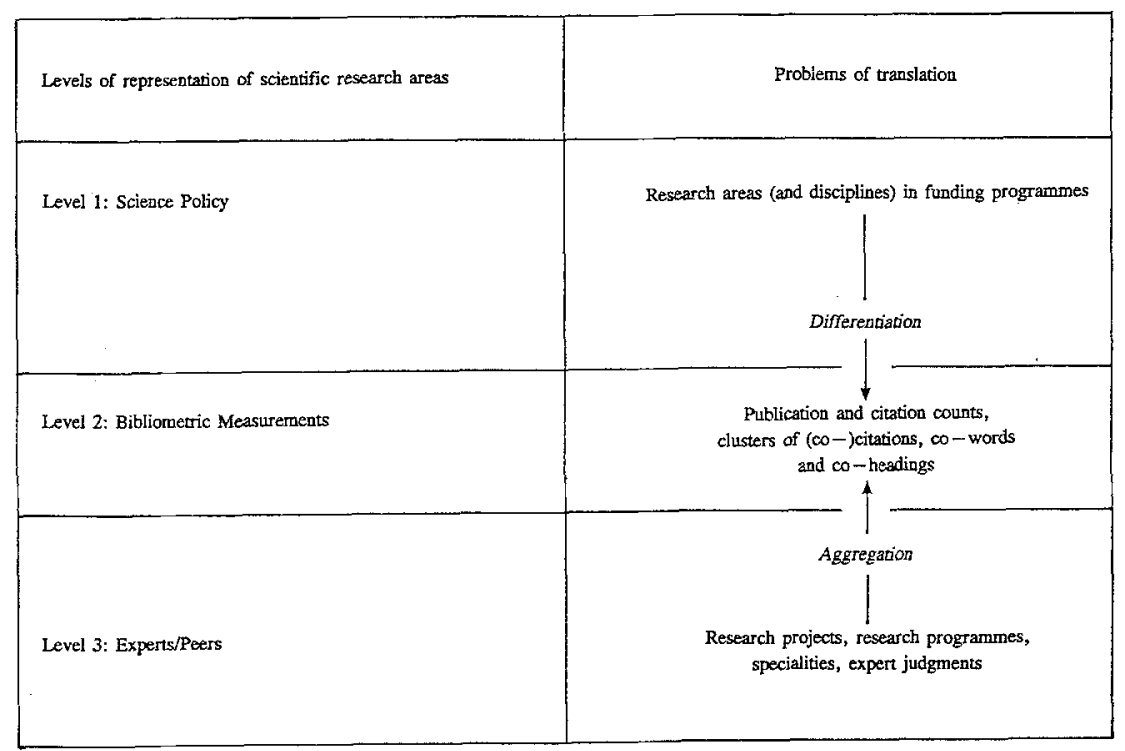

Fig. 1. Representations of science

Likewise, on the micro level (level 3) of specific fields the experts have a certain picture of their research areas, their delineations and relations to neighboring areas. They make their decisions on the basis of these pictures, and their existence is apparent when research projects have to be evaluated for which there is no expert.

Bibliometric data are a representation of science with an equally legitimate claim to reality which, figuratively speaking, enter on an intermediate level (level 2), i.e. between the macro representation of science policy and the micro representation of expert communication. It is produced by the acts of publication, the naming of articles, the labelling of journals. In that sense it is composed of self-referential acts of science. The 'foreign' element enters with the naming of clusters (in co-citation 
analysis) though one may debate this since cluster naming is done by experts as well. But surely it is a data processing, algorithm driven, artificial element.

If one compares the information content of the bibliometric representation with that of the others it may be said that it differentiates the codifications on the political level, and it aggregates and thus objectifies expert judgments. The crucial point is that each representation implies certain, mostly implicit, selections and reductions emanating from different functions but neither can claim a privileged authenticity. Two examples with which we will deal here illustrate this point. In one case we have a programme definition of marine sciences (Meeresforschung) which is shown with its different disciplinary segments (cf. Fig. 2), in the other we have three exemplary answers to a question put to experts who were asked to name the specialities involved in research on multiple sclerosis (ms), the disciplines to which they belonged, and the neighboring specialities (cf. Table 1). In particular, the latter show that relying on experts to delineate research specialities does not necessarily lead to a consensual picture.

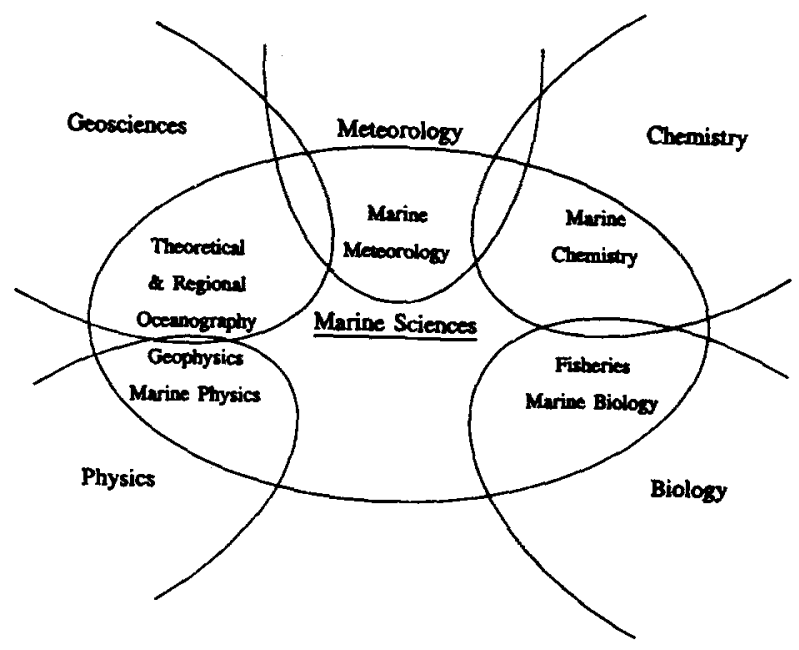

Fig. 2. Disciplinary scope of Marine Sciences (as definded in funding programmes) 
P. WEINGART et al.: WHICH REALITY DO WE MEASURE ?

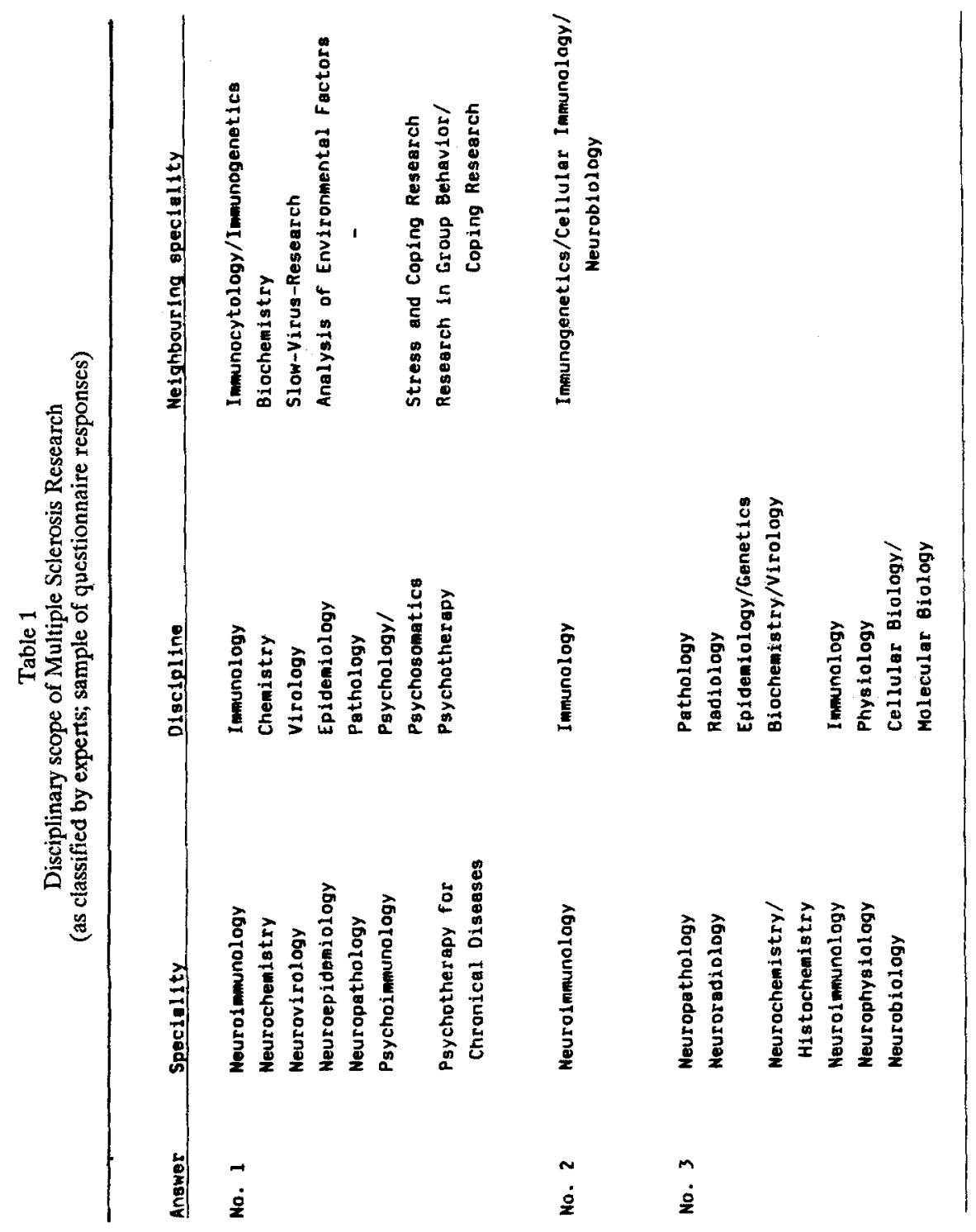




\section{Examples of different representations and the problem of translation}

This perspective shifts the problem of the representation of the "real picture" of science to that of making the bibliometric picture compatible with the others. This is, in fact, the pragmatic problem of translating the results of a bibliometric analysis, here co-citation analysis, into the categories of the other two levels, i.e. presenting them to policy makers and experts. While we will not provide a definitive solution we will try to describe some typical steps toward that objective.

One typical situation in applying bibliometric analysis to science is to choose the simplest and unaided approach to the data. With only two keywords ("Multiple" and "Sclerosis") a search was made in ISI's Co-citation Analysis SCI/SSCI 1984. This produced 12 co-citation clusters, mainly on the basic C1-level. (Left column in Table 2. Similarly, a search with nine fairly 'obvious' keywords in marine sciences produced 31 hits on the C2-level). Since an outsider like the analyst using bibliometric methods usually knows little or nothing about the field, he/she will have to translate the cluster titles back into the terminologies on level 1 or 3 of the model in Fig. 1. We also presented the list of ms-clusters to experts and asked for two 'acts of translation': a classification of type of research, and of discipline or speciality. In addition they were asked to identify additional keywords in each cluster title which also describe multiple sclerosis research. (Results combined in Table 2). It is evident that the new keywords would generate a whole array of new clusters with much more differentiated information on the field of multiple sclerosis.

The advantage of this procedure, where the naming of keywords is structured by the clusters, becomes apparent when one compares the results with those obtained by an unstructured enumeration of keywords by experts. A question on this point to experts produced a wide variety of words revealing vast differences of imagination among scientists about their fields. 12 experts in multiple sclerosis research identified 87 keywords describing the field: roughly two thirds of these keywords were named only once whereas only a third was named twice to six times.

Since the mere delineation of research fields already proves to be a matter of complex judgment one can expect that the evaluation of research or research groups will be even more ambiguous. Starting again with the bibliometric data one can select any one or several clusters from the list contained in Table 2 and obtain the institutional addresses from the respective 'research fronts'. (In our case the German institutions were extracted). Two steps are possible to arrive at a first (and very tentative!) evaluation: first, the traditional straightforward approach is to ask experts. 


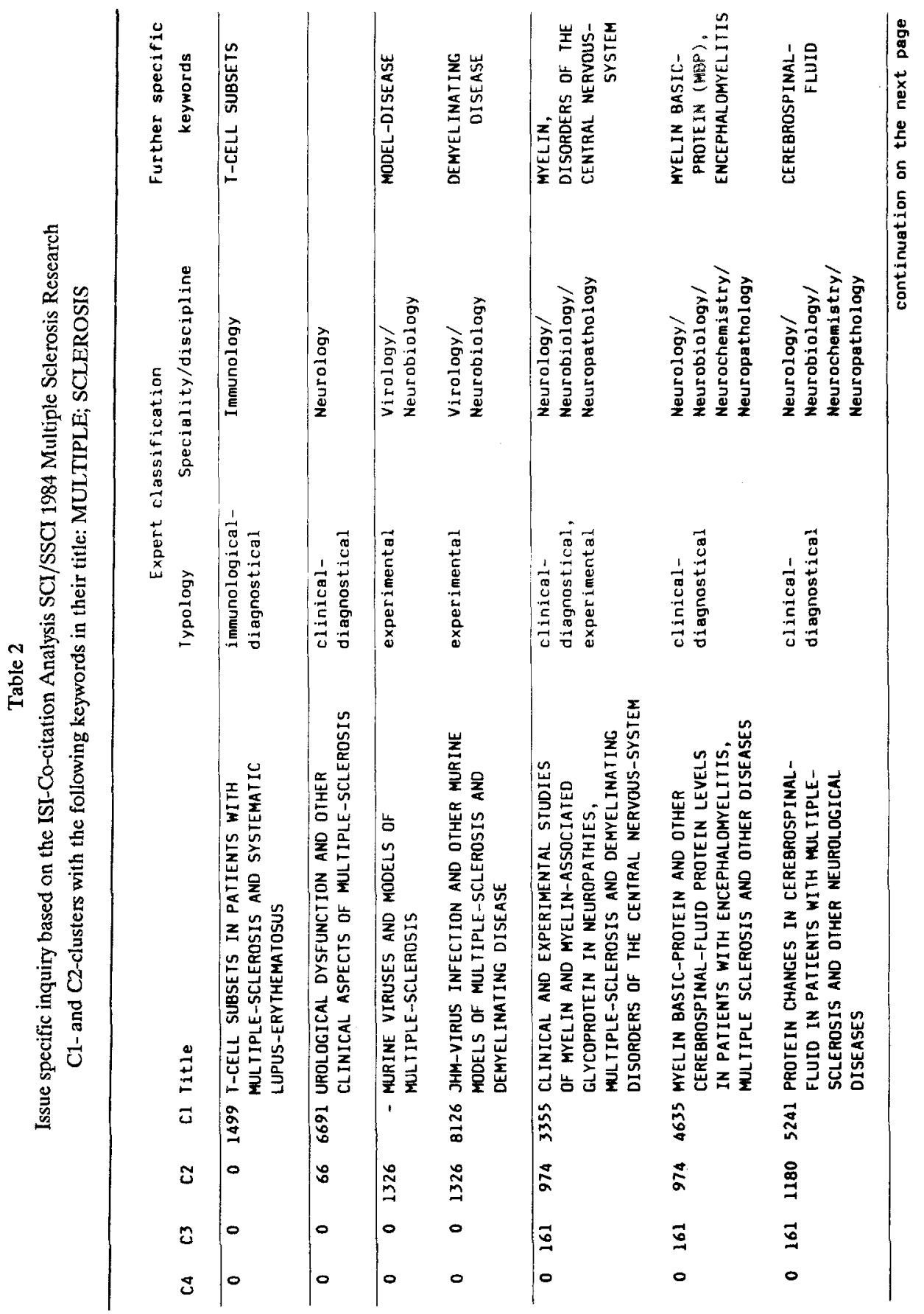


P. WEINGART et al.: WHICH REALITY DO WE MEASURE ?

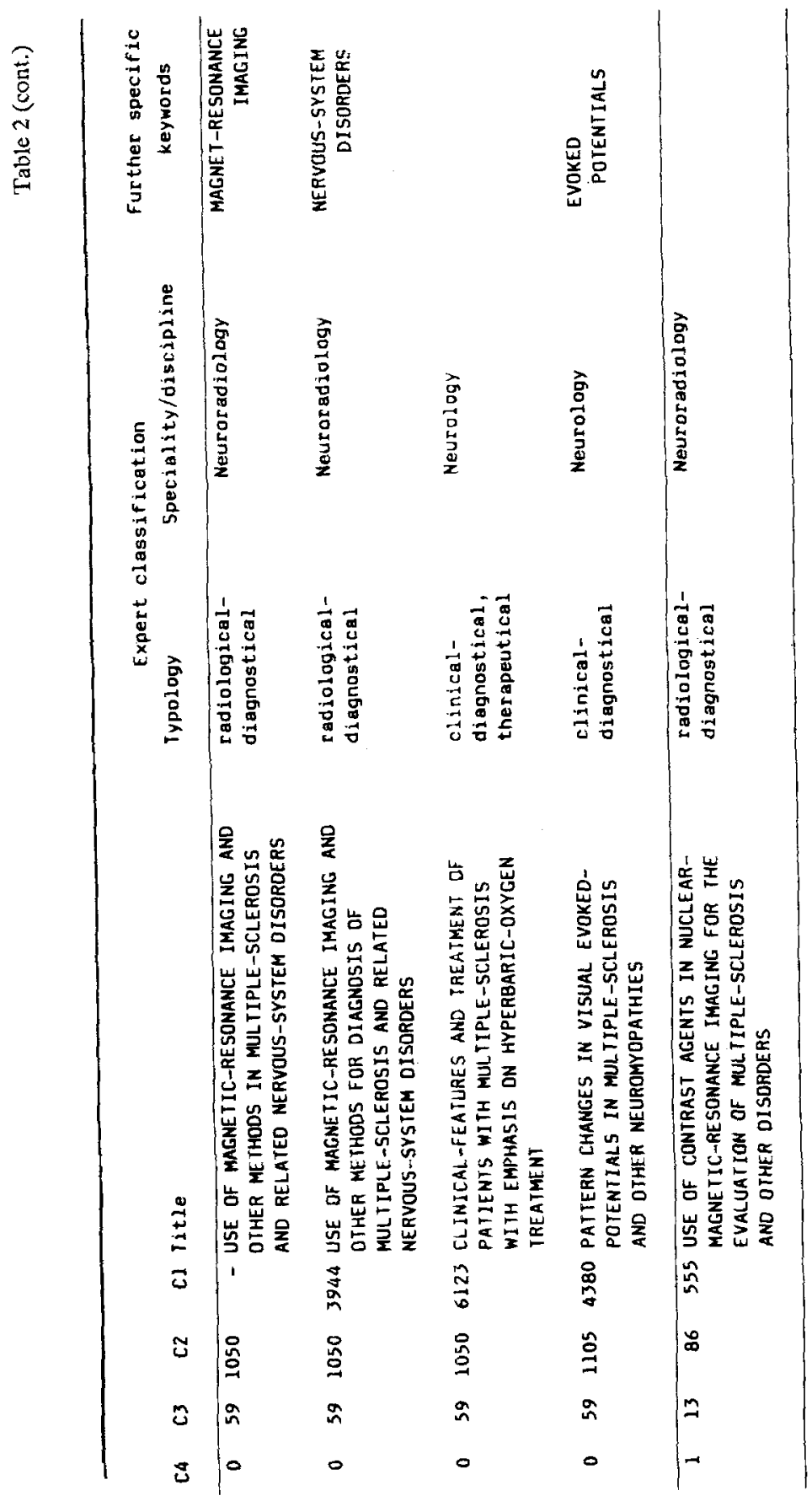


A result (though not in this case limited to the addresses in the clusters and thus only an illustration) is presented in Table 3 , showing the frequency distribution of institutions mentioned by sixteen interviewees, experts and funding organizations. The frequency of mentions to the neutral question: "list authors and/or research groups in Germany working in the area of research on ms" may then be taken to indicate reputation (cf. Table 3). A second approach based exclusively on bibliometric data is to look at the most highly cited documents in the cluster cores of a certain area and take the trouble to identify the institutional addresses of their authors from the Source Index of the SCI/SSCI or other data bases (cf. Table 4 demonstrating this for marine sciences).

Note that so far we have not differentiated between 'research fronts' and cluster cores. Lastly we will deal with a particular problem that may arise when using cocitation cluster analysis. In the identification of the institutional addresses of the major groups in ms-research (on the basis of "ms-clusters" as listed in Table 2) one was missing completely. This seemed to be a major deficiency of the method since the group appeared not only as one of the most important both in funding programmes and in the questionnaire but also as the only one with the explicit denomination of "multiple sclerosis" in its name (cf. Table 3 position 3). In such a case it is possible to take the route via the institutional address in question and select all clusters with at least one mention of that address (cf. Table 5). The resulting list was then presented to an expert member of the requisite research group asking him if the 'research fronts' represented the work of the group. It turned out that in the eyes of this expert the 'research fronts' do not provide a very reliable picture. A major reason is that with only one citation into the cluster core being sufficient to constitute them the fronts are too heterogeneous and demand a substantial translation effort from experts. However, the picture provided by the cluster cores is much more precise and in line with expert evaluation. This effect is even enhanced when cluster tracking is applied. Fig. 3 shows how over the course of several years the work of the particular group in question becomes the focus of a research field. 
Table 3

Important German research groups in Multiple Sclerosis Reseach

(nominations by peers and funding organizations;

sample with a frequency of nominations $>1$ )

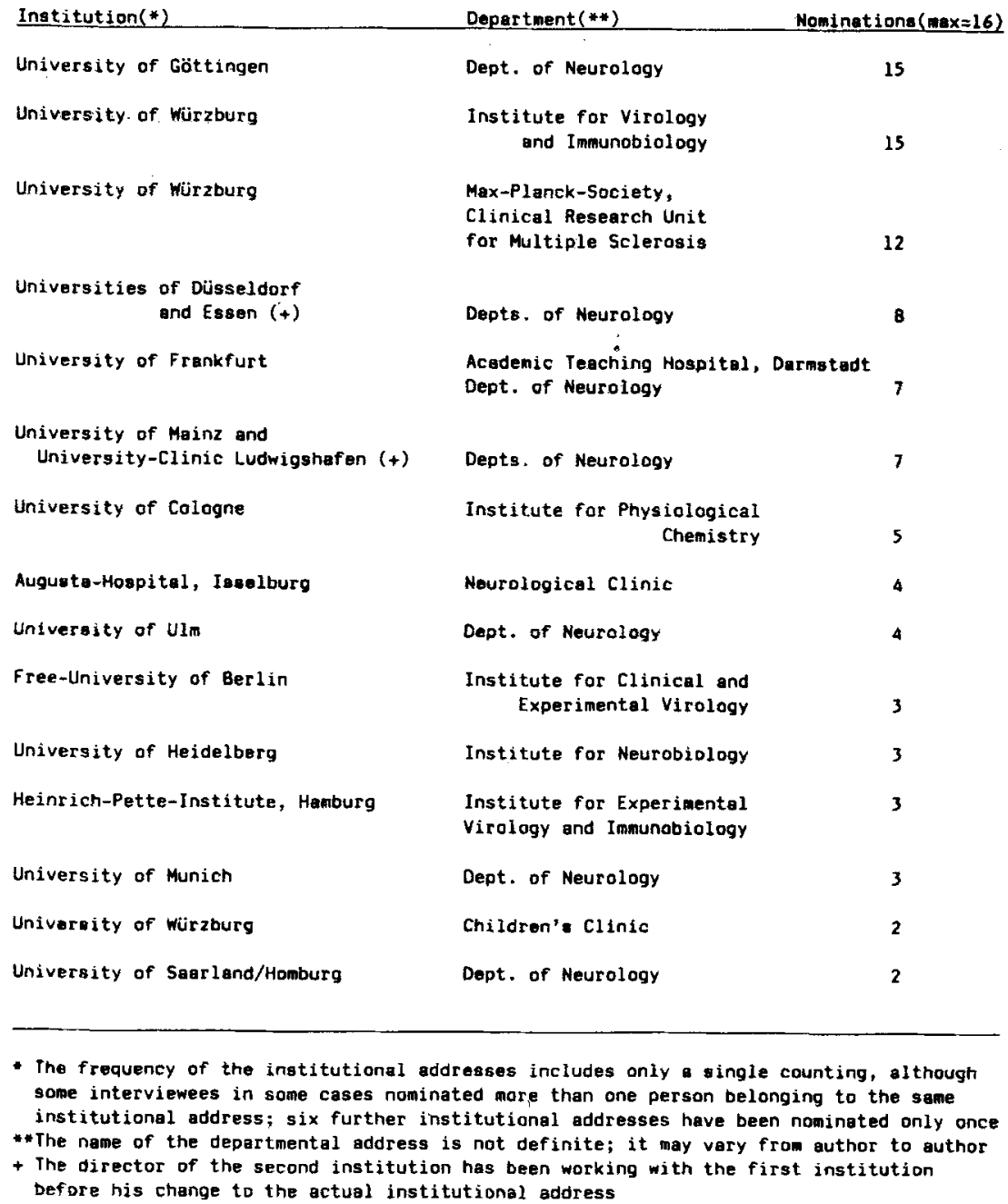


Table 4

ISI-Co-citation Analysis SCI/SSC1 1984

highly cited documents in Marine Sciences cluster cores

\begin{tabular}{|c|c|c|c|c|c|}
\hline \multirow[b]{2}{*}{ F1ret author } & \multicolumn{5}{|l|}{ Journal or } \\
\hline & Book title & Vol. & Page & Year & Citations \\
\hline - & 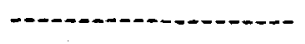 & -- & --- & $\cdots$ & $-+-\infty+\infty$ \\
\hline MOBBIE JE & APPL ENV MICROBIOL & 33 & 1225 & 77 & 77 \\
\hline PARSONS B & J GEOPHYS RES & 82 & 803 & 77 & 77 \\
\hline MCKENZIE D & EARTH PLANET SC LETT & 40 & 25 & 78 & 69 \\
\hline LABRECQUE JL & GEOLOGY & 5 & 330 & 77 & 67 \\
\hline SCHDENER TW & SCIENCE & 185 & 27 & 74 & 57 \\
\hline PEDLOSKY J & GEOPHYSICAL FLUID DY & & & 79 & 56 \\
\hline KARICKHOFF SW & WATER RES & 13 & 241 & 79 & 46 \\
\hline RASMUSSON EM & MON WEA REV & 110 & 354 & 82 & 46 \\
\hline MES5 G & REV GEOPHYS SPACE PH & 18 & 753 & 80 & 42 \\
\hline WIENS JA & AM SCI & 65 & 590 & 77 & 42 \\
\hline SCLATER JG & REY GEOPHYS SPACE FH & 18 & 269 & 80 & 45 \\
\hline
\end{tabular}

Institutional affiliation:

HOBEIE JE KARICKHOFF SW LABRECQUE $U$ MCKENZIE D NESS G PARSONS B PEDLOSKY J RASHUSSON EM SCMOENER TW SCLATER JG WIENS JA
Canede Ctr. Inland Weters, Vancouver, Cenade Environ. Res. Lab., U.S. Environ. Prot., Athens GA, USA Dept. Gool. Sci., Columbia Univ., Palisades NY, USA Dep. Geod. Geophys., Cambridge, GB Oregon State Univ., Corvalis OR, USA Dept. Earth a Planet. Sc., MIT, Cambridge, USA Woods Hole Dceanogr. Inst, Woods Hole MA, USA Nati. Weather Service, Meteorol. Ctr., Washington OC, USA Biol. Labs, Harvard Univ., Cambridge MA, USA Dep. Earth Planet. Science, MIT, Cambridge MA, USA Oregon State University, Corvalis OR, USA 
Table S

Institutional inquiry based on the ISI-Co-citation Analysis SCI/SSCI 1984

C1-clusters with at least one institutional address of the 'Clinical Research Unit for Multiple Sclerosis' (Würzburg) of the Max-Planck-Gesellschaft

\begin{tabular}{|c|c|c|c|c|}
\hline $\mathrm{CA}$ & C3 & $\mathrm{C2}$ & $\mathbf{C l}$ & Title \\
\hline 0 & 0 & 0 & 210 & $\begin{array}{l}\text { FACTORS PREDICTING DUTCOME OF SEVERE HEAD INJURY, COMA AMD } \\
\text { ACUTE TRAUMA CASES IN CHILOREN AMD DTHER PATIENT POPULATIONS }\end{array}$ \\
\hline 0 & 0 & 0 & 699 & $\begin{array}{l}\text { USE OF HUMAN KERATIN PROTEINS FOR THE STUDY OF LUNG-TUMOR-CELLS } \\
\text { AND DTHER NEOPLASMS }\end{array}$ \\
\hline 0 & 0 & 0 & 2511 & $\begin{array}{l}\text { EXPERIMENTAL MODELS FOR MONITORING CHANGES IN INTRACRANIAL-PRESSURE } \\
\text { AND CEREBROSPINAL-FLUID PRESSURE IN HYDROCEPHALUS }\end{array}$ \\
\hline 0 & 0 & 0 & 3120 & $\begin{array}{l}\text { CHARACTERIZATION, PURIFICATION AND ISOLATION OF DIFFERENT PROTEINS } \\
\text { FROM VARIDUS SPECIES USING MONOCLONAL-ANTIBODIES ANO OTHER METHODS }\end{array}$ \\
\hline$* 0$ & 0 & 0 & 4372 & T-CELL ACTIVATION FOLLOWING ANTIGEN PRESENTATION \\
\hline 1 & 14 & 20 & 32 & $\begin{array}{l}\text { CLINICAL AND EXPERIMENTAL STUDIES OF IMMUNE-RESPONSES WITHIN AN } \\
\text { IDIOTYPE NETWORK }\end{array}$ \\
\hline 1 & 14 & 37 & 1772 & $\begin{array}{l}\text { RELATIONSHIP. OF INTERLEUKIN-1 TO HUMAN T-CELL PROLIFERATION, } \\
\text { MACROPHACE ACTIVATION. AND OTHER INFLAMMATORY RESPONSES }\end{array}$ \\
\hline$* 1$ & 14 & 150 & 1994 & $\begin{array}{l}\text { FACTORS REGULATING EXPRESSION AND PRESENTATION OF ANTIGENS } \\
\text { BY MACROPHAGES AND OTHER IMMUNE SYSTEM CELLS }\end{array}$ \\
\hline 1 & 14 & 544 & 2020 & $\begin{array}{l}\text { ROLE OF DENDRITIC ANTIGENS IN PANCREATIC-ISLET TRANSPLANTATION } \\
\text { AND PROLONGATION OF ALLOGRAFT SURVIVAL }\end{array}$ \\
\hline I & 14 & 544 & 3435 & $\begin{array}{l}\text { MONOCLONAL-ANTIBODY ANALYSIS OF RAT T-CELLS AND THEIR CYTO-TOXIC } \\
\text { EFFECTS IN ALLOGRAFT-REJECTION }\end{array}$ \\
\hline 1 & 60 & 326 & 2555 & $\begin{array}{l}\text { EFFECTS OF ADENOSINE ON REGULATION OF CEREBRAL BLOOD-FLON } \\
\text { IN THE RAT BRAIN AND OTHER ANIMAL BRAINS }\end{array}$ \\
\hline
\end{tabular}

* Clusters relevant to the research progran of the Clinical Research Unit for MS in 1984 (interview response from the head of the unit) 
P. WEINGAR'T et al.: WHICH REALITY DO WE MEASURE ?
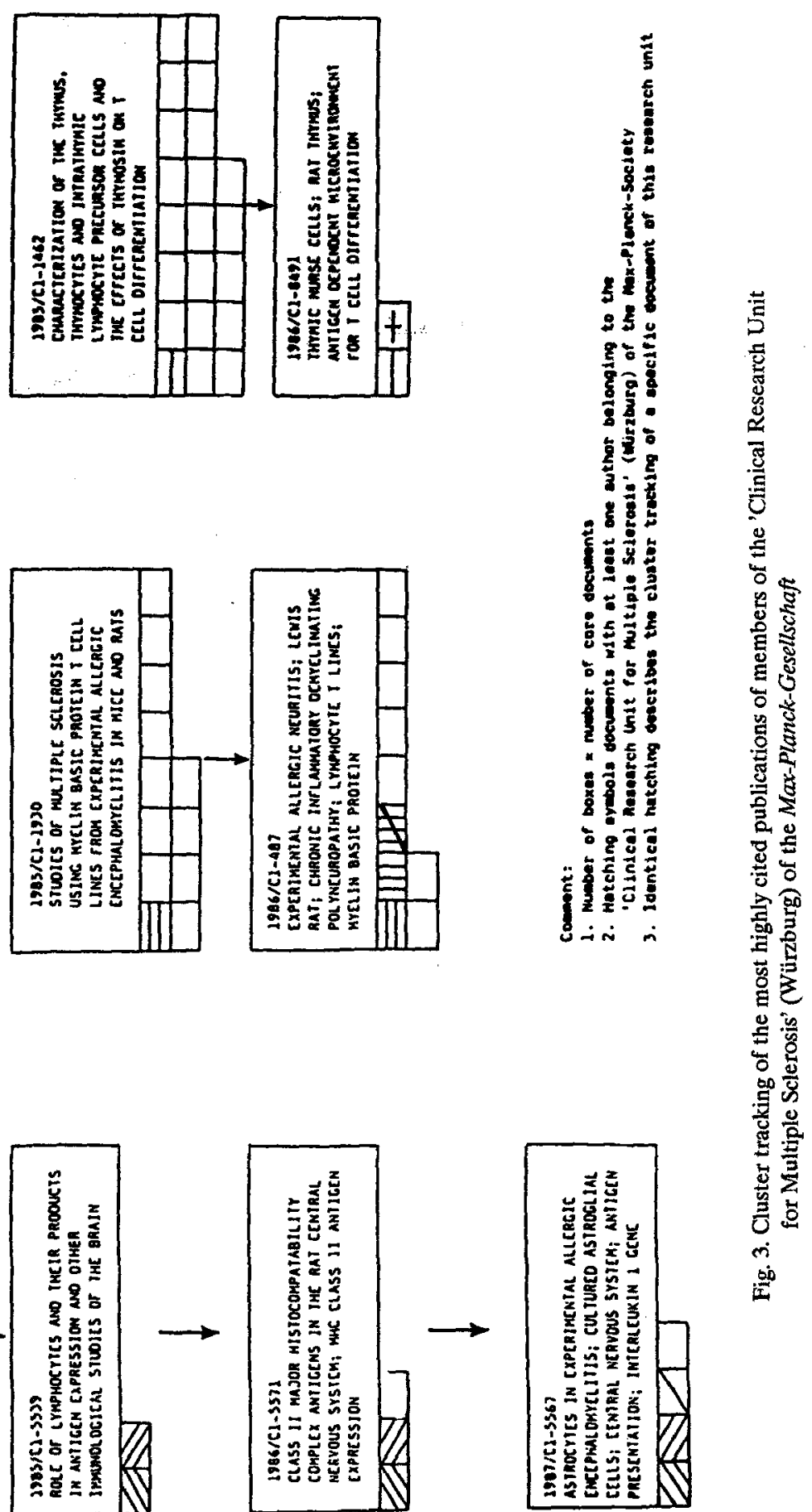


\section{Conclusion}

Concluding from these brief remarks it may be said that none of the approaches, programme delineations for science policy purposes, expert judgments in the review process, and bibliometric analyses can describe the limits of research fields or disciplines in an authoritative way and claim to capture the "essence" of science. If there is anything "essential" it is that the borderlines are fuzzy and in continuous flux. The crucial issue is to translate the different nomenclatures into each other and in this process make use of bibliometric data as an additional source of information.

\section{Note}

1. This article is based upon work commissioned by the German Federal Ministry for Research and Technology (BMFT), grant No. SWF0029 4. 